\title{
Cell-cycle progression and response of germ cell tumors to cisplatin in vitro
}

\author{
SANDRA MUELLER $^{1 *}$, MARCUS SCHITTENHELM $^{1 *}$, FRIEDEMANN HONECKER $^{3}$, \\ ELKE MALENKE $^{1}$, KIRSTEN LAUBER $^{2}$, SEBASTIAN WESSELBORG ${ }^{2}$, \\ JOERG T. HARTMANN $^{1}$, CARSTEN BOKEMEYER ${ }^{3}$ and FRANK MAYER ${ }^{1}$
}

\begin{abstract}
Departments of ${ }^{1}$ Oncology, Hematology, Immunology and Rheumatology, and ${ }^{2}$ Gastroenterology, Hepatology and Infectious Diseases, Medical Center, University of Tuebingen; ${ }^{3}$ Department of Oncology and Hematology, Medical Center University Hamburg-Eppendorf, Germany
\end{abstract}

Received January 18, 2006; Accepted March 14, 2006

\begin{abstract}
Testicular germ cell tumors (GCTs) are highly sensitive to cisplatin-based chemotherapy. It has been suggested that the chemosensitivity of GCTs can be partially attributed to the preference of apoptosis induction over a p21-mediated G1/S phase cell-cycle arrest following induction of p53. Since cell-cycle progression can be manipulated by a growing number of targeted agents, a thorough understanding of the impact of cell-cycle progression on drug-induced cell death might help to enhance the efficacy of chemotherapy. The aim of this study was to assess the cell-cycle dependence of cisplatin-induced cell death in an in vitro model of GCTs. Cell-cycle progression and induction of apoptosis were assessed by flow cytometry and Western blot analysis of PARP cleavage in the GCT derived cell lines, NT2 and 2102 EP, and compared with the breast carcinoma cell line MCF-7. Response to treatment was assessed in different phases of the cell cycle after synchronization by serum depletion and contact inhibition. Following cisplatin exposure, unsynchronized cells accumulated in G2/M after $28 \mathrm{~h}$. This arrest was reversible at sublethal cisplatin doses $(0.5-4.5 \mu \mathrm{M}$ for $2 \mathrm{~h})$. At higher concentrations, cells accumulated in G2 and died in G2/Marrest. A 2-h exposure of cells in $\mathrm{G} 2 / \mathrm{M}$ with $10 \mu \mathrm{M}$ cisplatin resulted in a higher apoptotic index $70 \mathrm{~h}$ after treatment (74 and $70 \%$ for NT2 and $2102 \mathrm{EP}$, respectively) compared to treatment in G1/S (34 and 38\%). Synchronized cells treated
\end{abstract}

Correspondence to: Dr Frank Mayer, Medizinische Klinik, Abteilung für Onkologie, Hämatologie, Immunologie und Rheumatologie, Otfried-Müller-Str. 10, D-72076 Tübingen, Germany

E-mail: frank.mayer@med.uni-tuebingen.de

\section{${ }^{*}$ Contributed equally}

Key words: germ cell tumors, cell-cycle synchronization, cisplatin, chemosensitivity, G2/M arrest in G1 showed PARP cleavage after $48 \mathrm{~h}$ following cisplatin exposure, whereas treatment in G2 resulted in PARP cleavage already after $24 \mathrm{~h}$. Cisplatin-induced cell death in GCTs is highly dependent on cell-cycle phase. All crucial events are restricted to the $\mathrm{G} 2 / \mathrm{M}$ phase: cisplatin-induced DNA-damage is sensed, the apoptotic process is initiated and eventually executed in this phase of the cell cycle. The cells are most sensitive to cisplatin in this phase of the cell cycle. As far as the development of targeted agents is concerned, inhibition of the cell cycle in G1/S phase is likely to result in a protective effect against cisplatin, whereas agents arresting cells in G2/M may exert a synergistic effect.

\section{Introduction}

In the Western world, testicular germ cell tumors (GCTs) represent the most common malignant solid tumor in males between 20 and 45 years of age (1). GCTs are highly sensitive to cis-diammino-dichloro-platin (cisplatin; CDDP)-based combination chemotherapy. Even patients with advanced metastatic disease can be cured by systemic treatment and secondary resection of residual masses if necessary (2). Nevertheless, in the metastatic situation, $10-15 \%$ of these patients finally die of their disease despite optimal treatment according to current standards. From a clinical point of view, GCTs are divided into seminomas and non-seminomas. The latter group can contain different histological subtypes. Mature teratoma differs from the remaining subtypes in its intrinsic chemotherapy resistance and non-invasive behavior.

The introduction of cisplatin into the treatment of GCTs has resulted in a dramatic increase of the cure rate. Yet, the mechanism of its cytotoxicity in GCT cells and mechanisms of chemotherapy resistance are only partially understood $(3,39)$. Immunohistochemical studies on GCT samples have raised the issue of the potential impact of cell-cycle control mechanisms on induction of an apoptotic response after chemotherapy. Many of the available studies focussed on p53 and related pathways $(4,5)$. p53 can mediate G1/S phase cell-cycle arrest via transactivation of p21. p21, in turn, inhibits the phosphorylation of the retinoblastoma gene product, RB, which is necessary for the entrance into the $S$ phase. As an 
alternative to cell-cycle arrest, p53 can induce apoptosis via a mitochondrial pathway, e.g. by induction of Bax (6).

It has been demonstrated that invasive GCTs hardly express $\mathrm{RB}$ and lack a correlation between p53 and p21. At the same time, p53-expression correlates with the apoptotic index. In contrast, mature teratoma components strongly express $\mathrm{RB}$, and p53-expression results in p21-expression (7-9). It has therefore been concluded that invasive GCTs preferably activate an apoptotic pathway following cellular stress sufficient to induce p53 rather than going into p21/RB-mediated G1/S phase cell-cycle arrest. This feature may contribute to the exquisite chemosensitivity of invasive GCTs (3). Vice versa, induction of p21/RB-mediated cell-cycle arrest could add to the intrinsic chemotherapy resistance of mature teratoma components. The rapid induction of apoptosis following exposure to cisplatin has been interpreted as an inherent property of the cell of origin (i.e. an early germ cell) to undergo programmed cell death (10). In view of the potentially disastrous consequences of passing on genetic defects to the next generation, it is tempting to speculate that the extreme sensitivity of germ cells to apoptotic stimuli serves as a kind of quality control.

It is well known that the sensitivity of cells towards radiation varies among the different phases of the cell cycle $(11,12,38)$. In contrast, the impact of cell-cycle progression on the effect of cytotoxic drugs has not been investigated to the same extent. Cells actively undergoing cell division are considered as being clearly more sensitive to most agents than resting cells. So far, there are no experimental data available on the effect of cell-cycle progression on the chemotherapy response of GCTs.

The anti-tumor activity of cisplatin is attributed to the formation of DNA adducts (13). Cell-cycle arrest after cisplatin application has been reported in the murine leukemia cell line, L1210, and confirmed in Chinese hamster ovary cells (14-16). Depending on the cisplatin concentration and the individual sensitivity of the cells, some cells recover and reenter the cell cycle or alternatively undergo programmed cell death $(13,17)$. However, the mechanisms linking the well described formation of cisplatin-DNA-adducts to the downstream events of programmed cell death are not defined yet.

With the development of tools enabling one to specifically manipulate cell-cycle progression, an understanding of the relationship between cell-cycle control and drug-induced cell death raises the prospect of increasing chemosensitivity by combining cell-cycle interactive agents with conventional chemotherapeutics. The aim of this in vitro study was to analyze the cell-cycle dependence of cisplatin-induced cell death in GCT cell lines in order to define the phase of the cell cycle during which these cells are most sensitive to the effects of cisplatin.

\section{Materials and methods}

Cell lines and reagents. Two established GCT cell lines derived from human embryonal carcinomas (NT2 and 2102 EP) and the human breast carcinoma cell line MCF-7, were analyzed. The GCT cell line, NT2 (ATCC CRL-1973), was maintained in DMEM with $4.5 \mathrm{~g} / 1$ glucose and stable glutamine (Invitrogen, Karlsruhe, Germany), the 2102 EP cell line (43) was cultured in DMEM/F-12 with $2 \mathrm{mM}$ L-glutamine (Invitrogen). MCF-7 cells were maintained in RPMI-1640 (Biochrom, Berlin, Germany). All culture media were supplemented with $10 \%$ heat-inactivated fetal calf serum (FCS, Biochrom), 100 units of penicillin/ml and $0.1 \mathrm{mg}$ streptomycin $/ \mathrm{ml}$ (Biochrom). Cells were grown as monolayers at $37^{\circ} \mathrm{C}$ in a $5 \% \mathrm{CO}_{2}$ atmosphere and maintained in the log phase. Cisplatin (CDDP) was obtained from Bristol-Myers Squibb (München, Germany).

Cell-cycle synchronization and cell-cycle phase arrest. Cellcycle synchronization was achieved by a non-pharmacological method using cell-to-cell contact inhibition in conjunction with serum depletion to induce cell quiescence (18). In brief, individual cells were spread out in 6-well plates and were grown to confluence. Then FCS-rich medium (10\%) was removed and cells were incubated in high density conditions with FCS-poor medium $(0.5 \%)$ for $48 \mathrm{~h}$ at $37^{\circ} \mathrm{C}$ in a $5 \% \mathrm{CO}_{2}$ atmosphere. Cells were subsequently released from the $\mathrm{G} 1 / \mathrm{S}$ arrest by replating at low density and addition of serum-rich medium. Subsequent synchronization in G2/M and the following G1/S phase was proven by flow cytometry according to the method of Nicoletti et al (19). Briefly, supernatant and adherent cells were harvested, washed and suspended in 0.2-0.5 ml hypotonic lysis buffer [0.1\% sodium citrate, $0.1 \%$ Triton X-100 (Sigma, Deisenhofen, Germany)] containing a propidium iodide (PI) stock solution $(50 \mu \mathrm{g} / \mathrm{ml}$ final concentration). Analysis of the cell cycle was performed on the FACScalibur (BD, Heidelberg, Germany) using the FSC/FL3 profile and CellQuest analysis software. After exclusion of necrotic debris, apoptotic and non-apoptotic (viable) nuclei were assessed.

Induction and quantification of apoptosis after cisplatin treatment. For determination of the cell-cycle dependence of apoptosis, cells were grown to confluency, synchronized and released by replating at low density as described before and left for $2 \mathrm{~h}$ to attach. Synchronization was confirmed by flow cytometry. Cells were treated with different concentrations of cisplatin for $2 \mathrm{~h}$ either directly in G1/S phase or after 20-24 h in $\mathrm{G} 2 / \mathrm{M}$ phase. For determination of apoptosis, the leakage of fragmented DNA from apoptotic nuclei was measured by the method of Nicoletti et al (see above) and subsequently analyzed by flow cytometry on the FACScalibur. Nuclei to the left of the $2 \mathrm{~N}$ peak containing hypodiploid DNA were considered as apoptotic. All experiments were repeated separately twice to ensure reproducibility. The average numbers of dead/apoptotic cells in G1 versus G2 phase treated cells were assessed.

Cell extracts and immunoblotting. Cleavage of poly(ADPribose) polymerase (PARP) as an indicator for caspasemediated apoptosis was detected by immunoblotting. Cells were treated and harvested at identical time-points as described above. Cells were washed in ice-cold PBS and lysed in RIPA buffer [9.1 mM Na $2 \mathrm{HPO}_{4}$-anhydrate, $1.7 \mathrm{mM} \mathrm{NaH} \mathrm{PO}_{4}$ and $150 \mathrm{mM} \mathrm{NaCl}, 1 \%$ (v/v) Nonidet P-40 (Sigma), $0.5 \%$ (w/v) sodium deoxycholate, $0.1 \%$ SDS (w/v), $20 \mu 1 / 1.5 \mathrm{ml}$ Protease-inhibitor cocktail P 8340 (Sigma) and $1 \mathrm{mM}$ PMSF (Sigma). Subsequently, proteins were separated under reducing conditions on an SDS polyacrylamide gel and electroblotted (semi-dry blot) to a polyvinylidene difluoride (PVDF) 


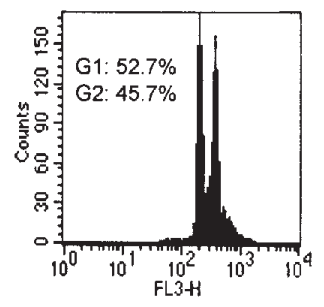

$0.1 \times 10^{6} /$ well

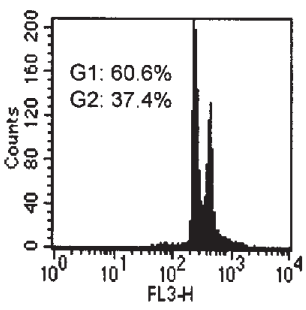

$0.5 \times 10^{6} /$ well

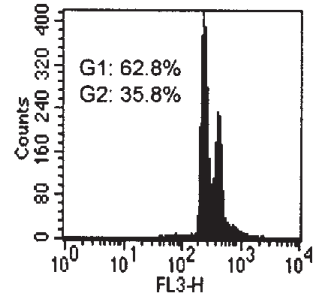

$1.5 \times 10^{6} /$ well

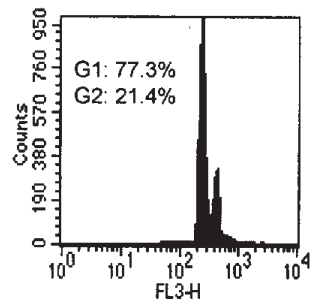

$3.0 \times 10^{6} /$ well

\section{Cell density in 6-well plates before incubation}

Figure 1. Flow cytometric analysis of the degree of cell-cycle synchronization of the germ cell tumor derived cell line, NT2. Cells were spread out in 6-well plates (initial cell densities ranged from 0.1 to $3.0 \times 10^{6}$ cells/well) and analyzed after $48 \mathrm{~h}$ of incubation. Note, cells accumulated in G1 when plated at a high cell density.

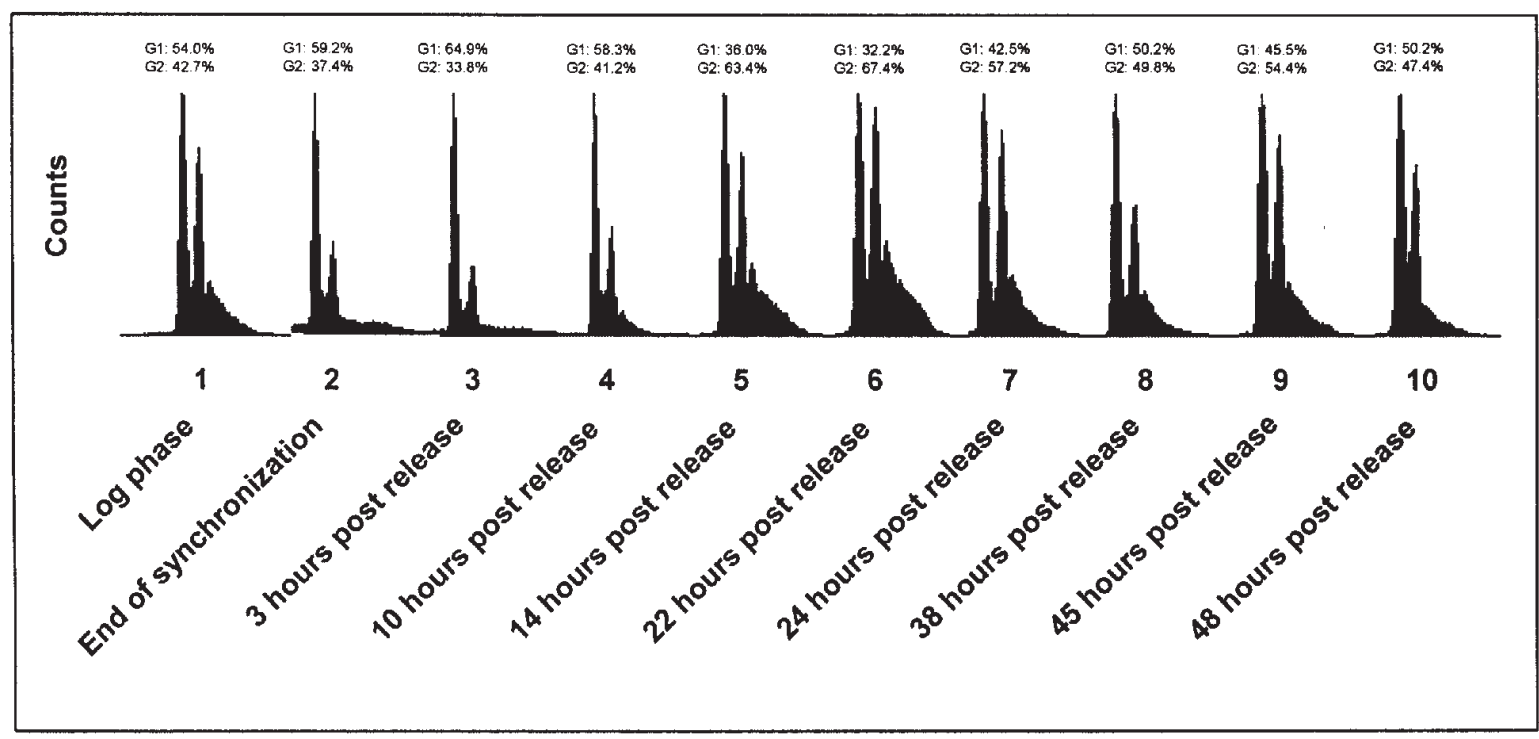

Figure 2. Flow cytometric analysis of the cell-cycle distribution of synchronized NT2 cells. 1, log phase; 2, end of synchronization, i.e. release by replating in low-density and addition of serum-rich medium; $3,3 \mathrm{~h}$ post release; $4,10 \mathrm{~h}$ post release; $5,14 \mathrm{~h}$ post release; $6,22 \mathrm{~h}$ post release; $7,24 \mathrm{~h}$ post release; $8,38 \mathrm{~h}$ post release; $9,45 \mathrm{~h}$ post release; $10,48 \mathrm{~h}$ post release.

membrane (Amersham Biosciences GmbH, Freiburg, Germany). Membranes were blocked for $1 \mathrm{~h}$ with $2 \%$ nonfat dry milk powder in PBS containing $0.05 \%$ Tween-20 followed by overnight incubation at $4^{\circ} \mathrm{C}$ with a rabbit polyclonal antibody against cleaved PARP (anti-PARP p85 Fragment pAb; Promega GmbH, Mannheim, Germany) and p53 (Dako, Hamburg, Germany). To verify protein loading on the gel and homogenous blotting, an anti-actin antibody (Sigma) was used as control. Membranes were washed six times with PBS plus $0.05 \%$ Tween-20 and incubated with the respective peroxidase-conjugated affinity-purified secondary antibody (Dako) for $1 \mathrm{~h}$. Following washing, the reaction was developed by enhanced chemiluminescent staining using ECL reagent (Amersham).

Caspase activity assay. Cytosolic cell extracts were prepared by lysing cells in RIPA buffer as described above. Activity of caspases 3 and 7 was determined by incubation of cell lysates with $50 \mu \mathrm{M}$ of the fluorogenic substrate, DEVD-AMC (Nacetyl-Asp-Glu-Val-Asp-aminomethylcoumarin) (Biomol, Hamburg, Germany), in $200 \mu 1$ buffer containing $50 \mathrm{mM}$ HEPES (pH 7.3), $100 \mathrm{mM} \mathrm{NaCl}, 10 \%$ sucrose, $0.1 \%$ CHAPS and $10 \mathrm{mM}$ DTT. The release of aminomethylcoumarin was measured kinetically by fluorometry using an excitation wavelength of $360 \mathrm{~nm}$ and an emission wavelength of $475 \mathrm{~nm}$. Caspase activity was determined as the slope of the resulting linear regressions and expressed in arbitrary fluorescence units per minute.

\section{Results}

Non-pharmacological cell-cycle synchronization. Initially, the method of synchronization of the human germ cell tumor cell lines, NT2 and $2102 \mathrm{EP}$, and of the human breast cancer 


\section{Concentration-related G2 arrest in NT2 cells}
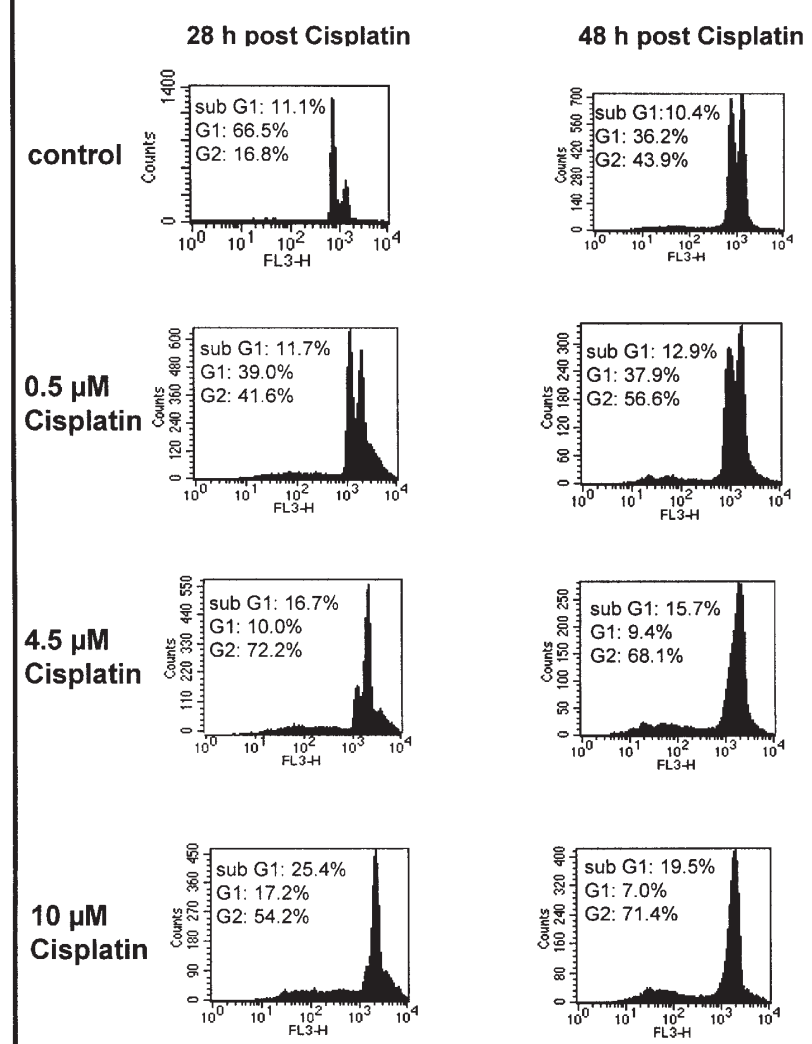

Figure 3. Flow cytometric analysis of the cell cycle of unsynchronized NT2 cells, 28 and $48 \mathrm{~h}$ after treatment with different concentrations of cisplatin $(0.5,4.5$ and $10 \mu \mathrm{M})$ for $2 \mathrm{~h}$. Nuclei left of the $2 \mathrm{~N}$ peak containing hypodiploid DNA were considered as apoptotic (sub-G1).

cell line MCF-7 by non-pharmacological means was optimized. The influence of cell-to-cell contact inhibition on cell-cycle synchronization for the embryonal carcinoma cell line, NT2, is demonstrated in Fig. 1. The degree of cell-cycle arrest was related to the initial cell density of inserted cells in 6-well plates in culture after $48 \mathrm{~h}$ of incubation.

In NT2 cells, cell-to-cell contact inhibition combined with serum starvation conditions for $48 \mathrm{~h}$ caused proliferation arrest in G1 compared to cells in the log growth phase (Fig. 2). Ten hours after serum release, a continuous increase of cells entering G2 was observed. Fig. 2 also demonstrates the polyploidy for cells in the log phase before synchronization, a decrease for arrested cells in G1 and an increase for cells entering $\mathrm{G} 2$.

Comparable results were found for $2102 \mathrm{EP}$ cells and the human breast carcinoma cell line, MCF-7, after releasing cells from synchronization conditions by contact inhibition and serum starvation (data not shown). These data confirm the usefulness of the model used for cell-cycle synchronization.

Influence of cisplatin on cell-cycle progression. Cisplatin induced cell-cycle arrest in a dose-dependent manner in the

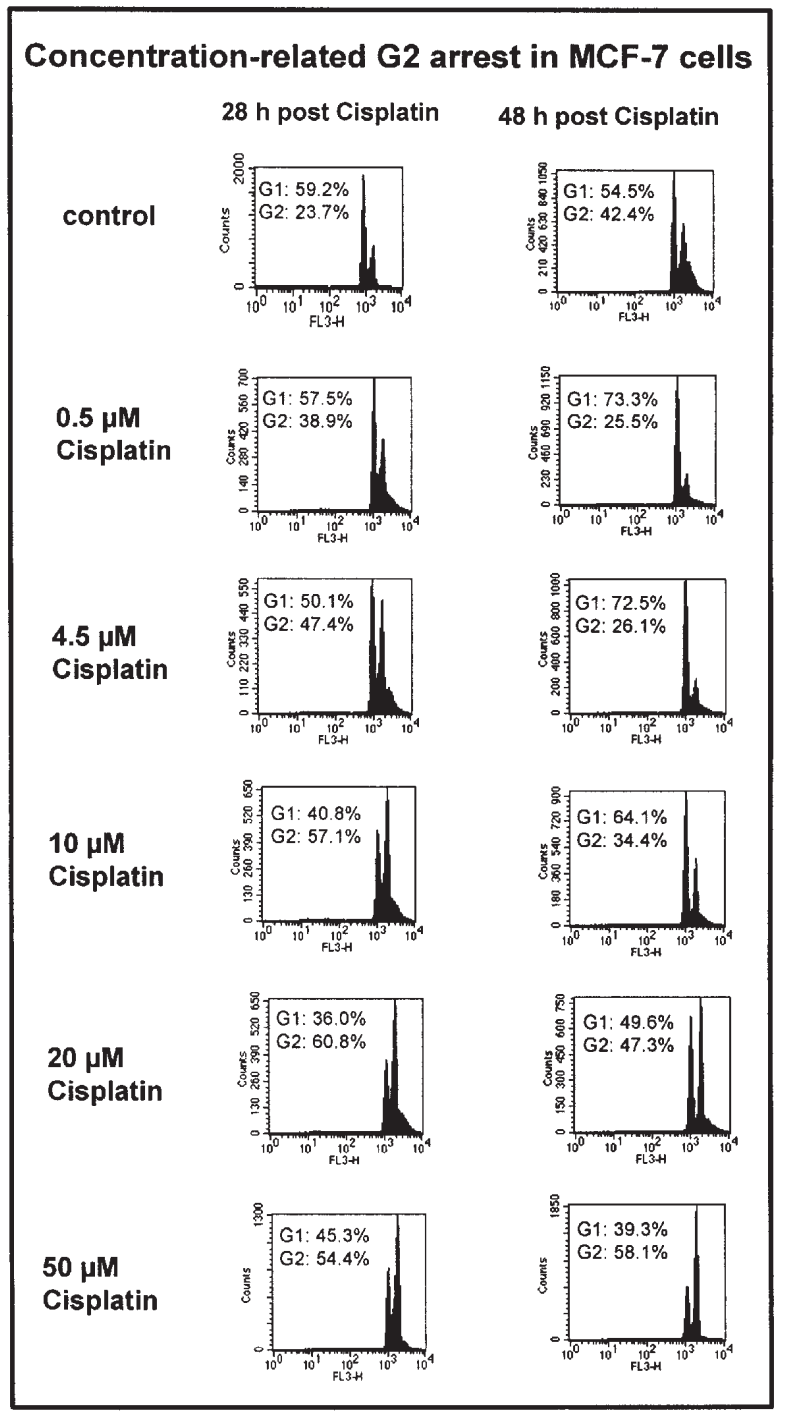

Figure 4. Flow cytometric analysis of the cell cycle of unsynchronized MCF-7 cells, 28 and $48 \mathrm{~h}$ after treatment with different concentrations of cisplatin $(0.5,4.5,10,20$ and $50 \mu \mathrm{M})$ for $2 \mathrm{~h}$.

germ cell tumor cell line, NT2, and the human breast carcinoma cell line, MCF-7, in unsynchronized cells. Cells cultured in the log phase were treated with cisplatin for $2 \mathrm{~h}$. After cisplatin application, NT2 cells accumulated in G2/M. The arrest was reversible when sublethal cisplatin doses $(0.5-4.5 \mu \mathrm{M})$ were applied. At a higher cisplatin concentration $(10 \mu \mathrm{M})$, cells accumulated in $\mathrm{G} 2$, and subsequently progressed to apoptosis out of the G2/M arrest (Fig. 3).

In the human breast carcinoma cell line, $\mathrm{MCF}-7$, cisplatin induced reversible $\mathrm{G} 2$ arrest at cisplatin concentrations of 0.5-20 $\mu \mathrm{M}$. At these concentrations, cells were still able to reenter the cell cycle. At a higher concentration $(50 \mu \mathrm{M})$, cells remained in G2 arrest, indicated by a stable or increasing G2 peak $48 \mathrm{~h}$ after administration of cisplatin (Fig. 4).

Influence of the cell-cycle phase on the sensitivity of germ cell tumor-derived cell lines towards cisplatin. To determine the cell-cycle dependence of cisplatin-induced apoptosis, cells were grown to confluency and synchronized. Fig. 5 shows NT2 cells in a transient G1 arrest after release from synchronization. Cells were treated with $10 \mu \mathrm{M}$ cisplatin for 
A

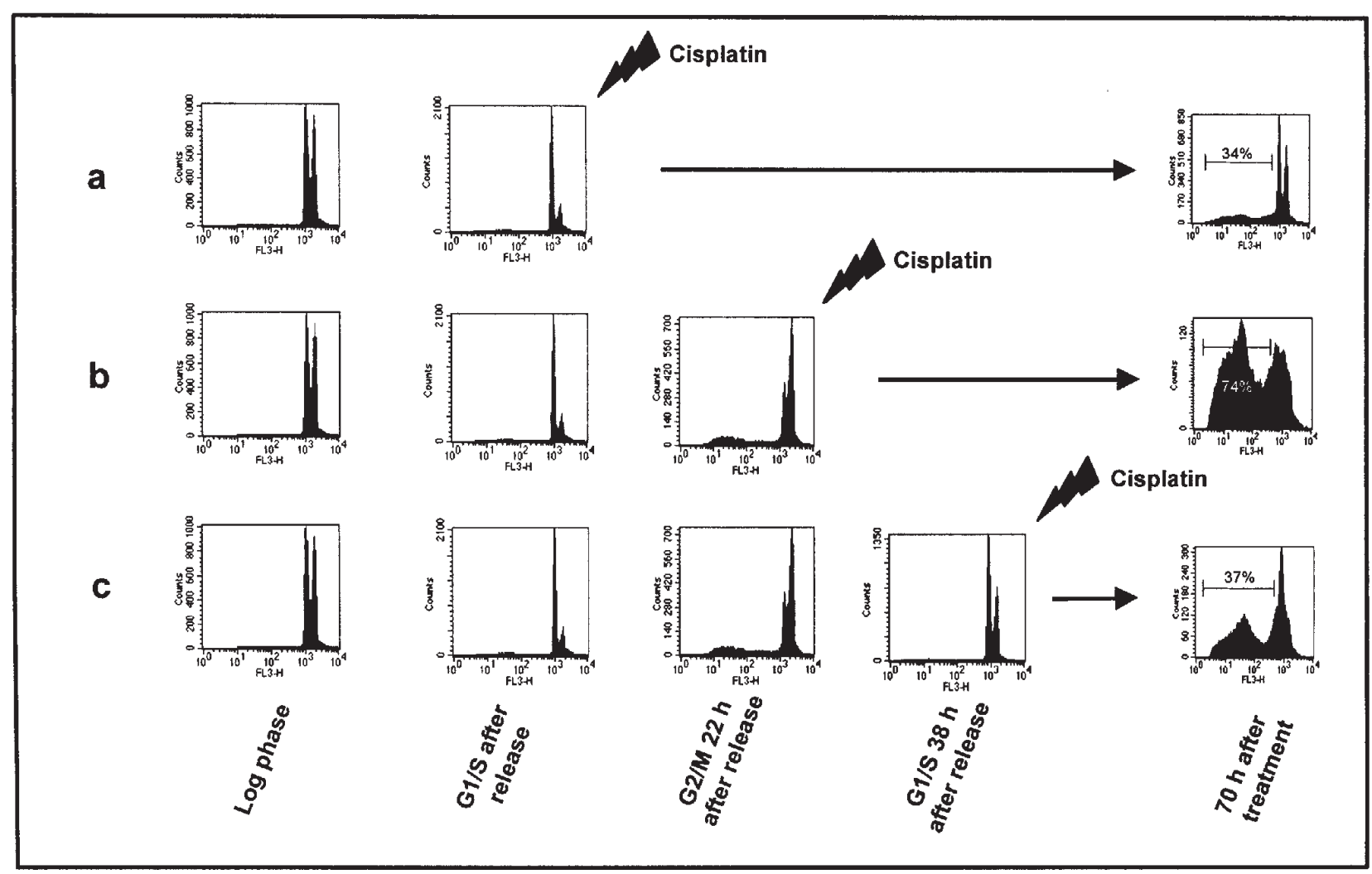

B

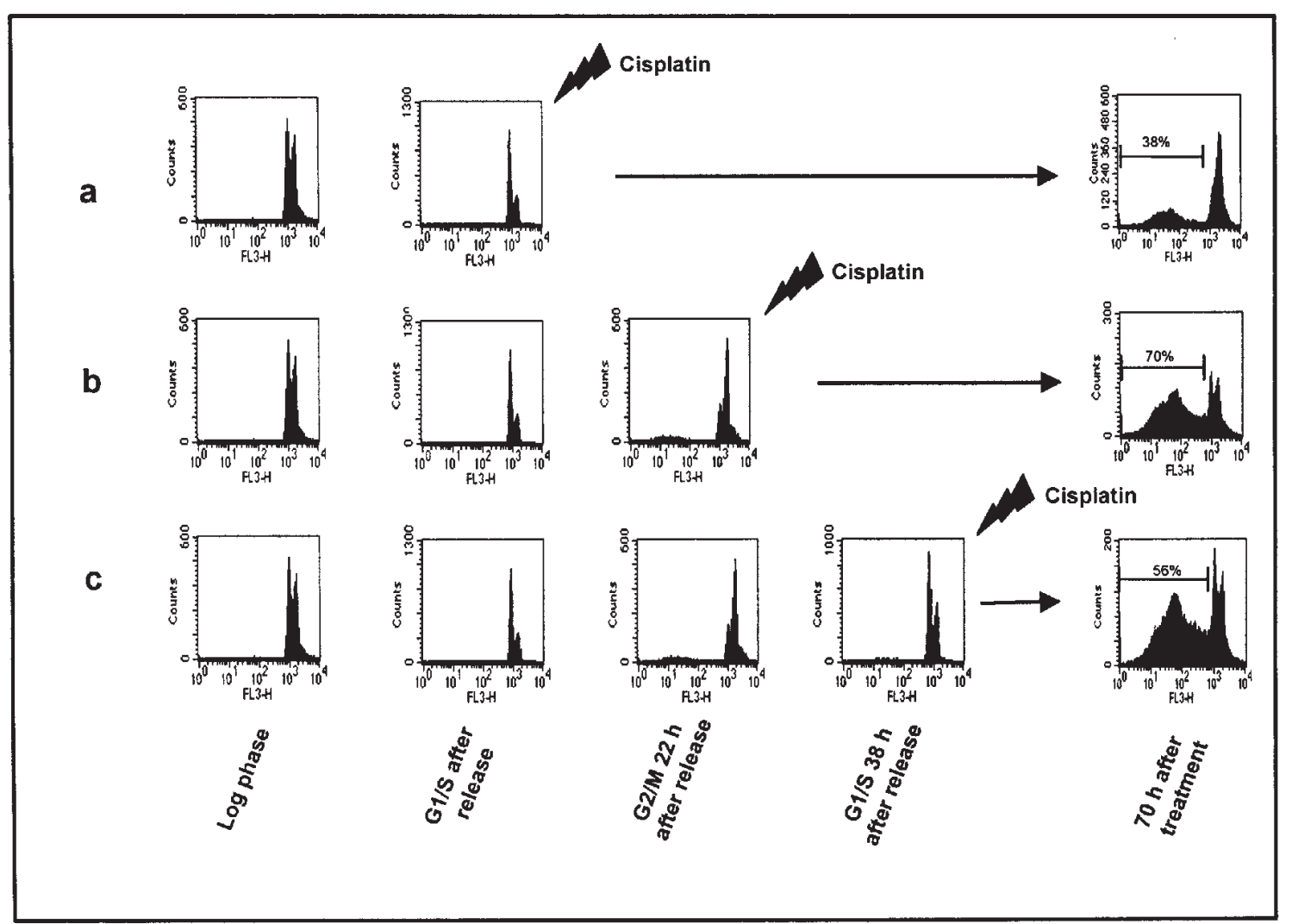

Figure 5. Flow cytometric analysis of the cell cycle of NT2 (A) and $2102 \mathrm{EP}$ (B) cells $70 \mathrm{~h}$ after cisplatin treatment (10 $\mu \mathrm{M}, 2 \mathrm{~h})$ of synchronized cells in transient G1 and G2 arrest. a, Cells were grown to confluency and synchronized in G1. After release from synchronization, cells were replated and treated with cisplatin. b, $22 \mathrm{~h}$ after releasing cells from G1-synchronization, cells reached G2 and were treated with cisplatin. c, $48 \mathrm{~h}$ after releasing cells from G1-synchronization, cells reached the second G1-peak and were treated with cisplatin.

2 h. Synchronized cells treated in G1 with cisplatin showed an apoptotic index of $34 \%$ after $70 \mathrm{~h}$ (NT2; Fig. 5A) or $38 \%$ (2102 EP; Fig. 5B), respectively. Cells treated in G2 for the same period of time revealed an apoptotic index of $74 \%$ (NT2; Fig. 5A) and 70\% (2102 EP; Fig. 5B), respectively. Treatment of cells in the second G1-peak $38 \mathrm{~h}$ after the release resulted 


\section{A}

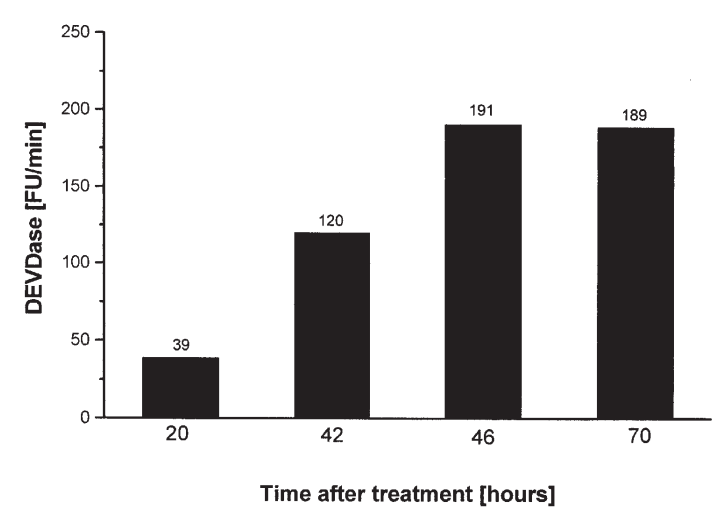

B

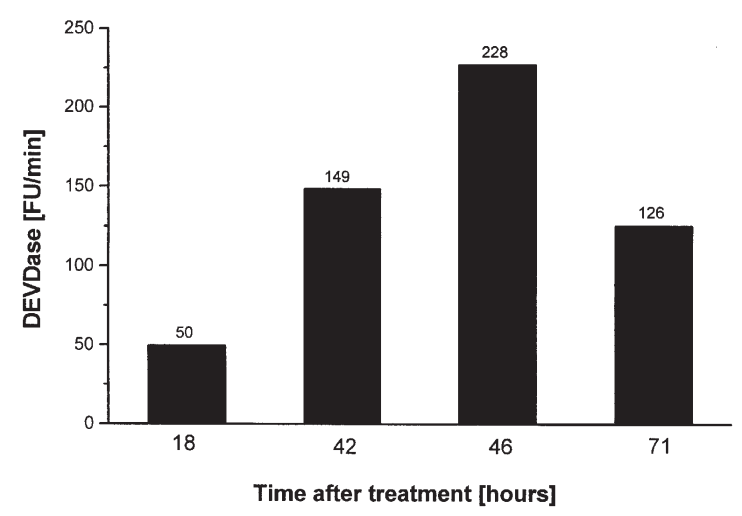

Figure 6. DEVDase activity, expressed as arbitrary fluorescence units per minute $[\mathrm{FU} / \mathrm{min}]$ of synchronized NT2 cells after cisplatin treatment $(10 \mu \mathrm{M}$, $2 \mathrm{~h})$. A, treated in G1. B, treated in G2.

in $37 \%$ apoptotic cells $70 \mathrm{~h}$ after treatment for NT2 (Fig. 5A) and $56 \%$ for $2102 \mathrm{EP}$ (Fig. 5B).

Influence of cell-cycle progression on the kinetics of apoptosis after cisplatin. Cisplatin induced caspase-3- and -7-like activity was measured by a fluorogenic DEVDase activity assay in cells treated in G1 and G2 phase, respectively. DEVDase activity increased up to $46 \mathrm{~h}$ after application of $10 \mu \mathrm{M}$ cisplatin for $2 \mathrm{~h}$ in both cell-cycle phases (Fig. 6). Treatment in G2 yielded higher DEVDase activity compared to treatment in G1. The results are in line with a delayed onset of apoptosis after treatment in G1.

Comparison of cisplatin-induced PARP cleavage in different phases of the cell cycle is shown for 2102 EP cells in Fig. 7. PARP cleavage as a downstream event of effector caspase activation was observed $48 \mathrm{~h}$ after cisplatin treatment of 2102 EP cells treated in G1 and the following G1. Cells treated in G2 demonstrated cleavage of PARP after $24 \mathrm{~h}$. Seventy hours after the cells had been treated, PARP was almost completely degraded in the G2 and the following G1 phase.

Additionally, we analyzed the p53-induction after cisplatin exposure. 553 was already induced $24 \mathrm{~h}$ after cisplatin administration in G2 in NT2 and 2102 EP cells. Compared to G1, induction of p53 did not occur before $48 \mathrm{~h}$ after treatment (data not shown).

\section{Discussion}

GCTs are characterized by an exceptional sensitivity to cisplatin-based chemotherapy. Based on immunohistochemical data gained from the analysis of tumor samples from untreated patients, we have previously proposed a model attributing the chemosensitivity of invasive GCTs to an abdication of $\mathrm{p} 21 / \mathrm{RB}$-mediated $\mathrm{G} 1 / \mathrm{S}$ phase cell-cycle arrest following the induction of p53. Vice versa, the intrinsic resistance of mature teratomas could, among other mechanisms, be caused by higher $\mathrm{p} 21$ - and RB-expression resulting in $\mathrm{G} 1 / \mathrm{S}$ phase arrest (3). If $\mathrm{G} 1 / \mathrm{S}$ phase arrest prevents the action of cisplatin, the drug should exert its action in a cellcycle dependent manner, and in a subsequent phase of the cell cycle.

In order to analyze the impact of cell-cycle progression on the activity of cisplatin, a synchronized population of cells was required. Adherent cell lines divide continuously, resulting in high cell density and cell-to-cell contact. At this point, non-transformed cells undergo reversible arrest in early G1 (20). Cells failing to go into G1 arrest start to overgrow and show cobblestone formations. This was also seen in the

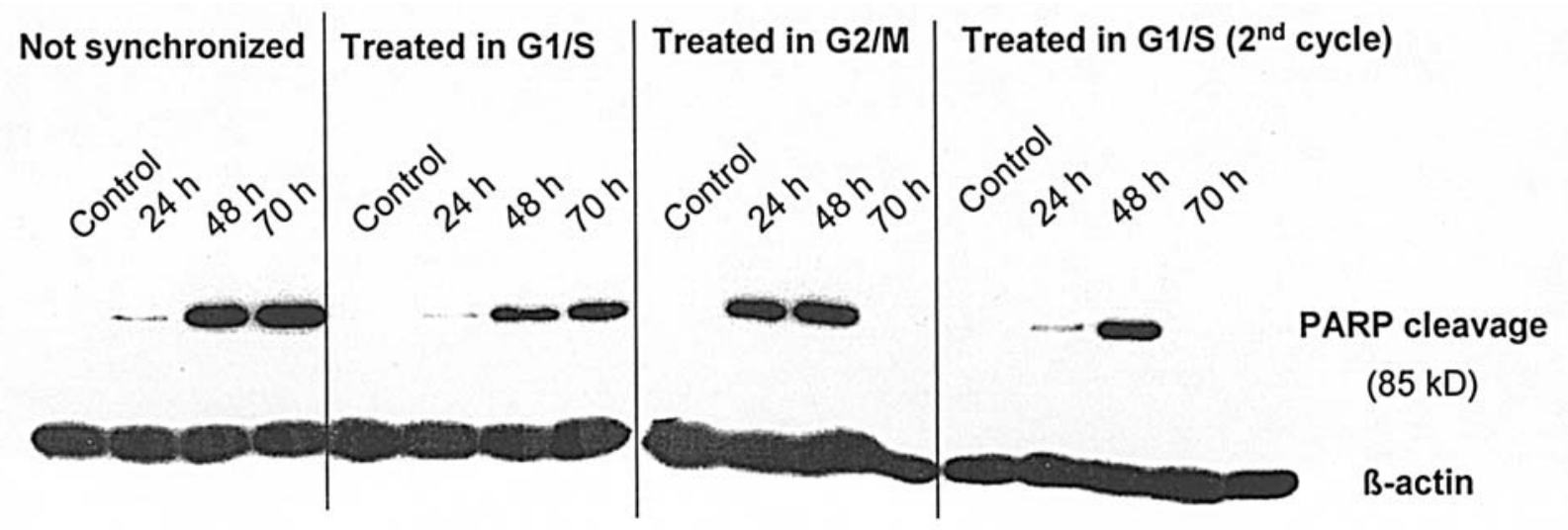

Figure 7. Western blot analysis with anti-PARP p85 fragment pAb and anti-actin control after cisplatin treatment (10 $\mu \mathrm{M}, 2 \mathrm{~h})$ of $2102 \mathrm{EP}$ cells. $85 \mathrm{kDa}$, cleaved PARP. 
used GCT cell lines. As a modified approach, cell-to-cell contact inhibition plus serum withdrawal can help to yield an increased number of cells in the early stage of G1 (18). Transition from G0 quiescence to early G1 phase is, in part, mediated and facilitated through mammalian D-type cyclins that are upregulated in the presence of growth factors (21-23). By removing mitogenic serum factors from cell culture medium, serum deprivation can result in G0 quiescence $(24,25)$. Releasing cells from cell synchrony is achieved by addition of serum to stimulate cell-cycle progression. The combination of cell-contact inhibition with serum depletion was optimized for the cell lines used in our experiments and yielded sufficient cell-cycle synchronization for the experiments as shown in Figs. 1 and 2. This method prevents drug promoted side effects, such as dissociation of nuclear and cytoplasmic cell-cycle processes, disruption in the metabolic state of the cell, and cell death (26-29). Stressinduced interacting artefacts in block-and-release methods occur especially in the first cell cycle after release from the block. The further cycles are relatively free of artefacts (30).

Following exposure to cisplatin, unsynchronized GCT cells were arrested to almost $100 \%$ in G2/M. In concentrations not sufficient to induce apoptosis, this arrest was reversible and the cells reentered the cell cycle after removal of cisplatin from the medium. Vice versa, cell death did not occur without prior $\mathrm{G} 2 / \mathrm{M}$ arrest. Cisplatin-induced $\mathrm{G} 1 / \mathrm{S}$ arrest was not observed at any drug concentration applied in GCT cell cultures. In contrast, the breast cancer cell line, MCF-7, showed $\mathrm{G} 1 / \mathrm{S}$ arrest when sublethal cisplatin concentrations were used. Higher doses also produced G2/M arrest preceding cell death. Due to a lack of caspase 3 expression, MCF-7 cells do not show DNA-degradation and, thus, hypodiploid apoptotic nuclei can not be demonstrated in FACS analyses. Collectively, the data on cell-cycle progression in unsynchronized GCT cells following cisplatin exposure indicate that execution of apoptosis takes place during G2/M arrest. However, the data at this point do not rule out the possibility that sensing of the critical DNA-damage might take place earlier during the cell cycle and that cells have to progress to the $\mathrm{G} 2 / \mathrm{M}$ phase to start the cell death program.

In order to address this possibility, GCT cells were synchronized and treated in different phases of the cell cycle. Assuming that the critical DNA-damage is sensed during $\mathrm{G} 1 / \mathrm{S}$, cells treated in $\mathrm{G} 2 / \mathrm{M}$ would have to pass the $\mathrm{G} 1 / \mathrm{S}$ checkpoint before the apoptotic cascade is activated. In this case, apoptosis of cells treated in G1/S should be observed earlier than apoptosis of cells treated in $\mathrm{G} 2 / \mathrm{M}$. The results of our experiments, however, point in a different direction. Cells treated in G2/M showed PARP-cleavage markedly earlier than those treated in G1/S. Passage through G1/S was not necessary for the cells to become apoptotic. These data clearly demonstrate that, in GCT cells, not only the execution of apoptosis but also initiating events take place in the $\mathrm{G} 2 / \mathrm{M}$ phase of the cell cycle.

In view of the importance of the $\mathrm{G} 2 / \mathrm{M}$ phase for the induction of apoptosis of the GCT-derived cell lines, we finally tested whether cells are more sensitive to the effects of cisplatin when treated in this particular phase of the cell cycle. For both cell lines investigated, a higher cell kill was achieved by short-term exposure during G2 compared to treatment in G1.
This held also true for cells treated in a subsequent G1 peak after release from cell-cycle arrest, thus ruling out a stunning effect of the synchronization process. The differences observed in cell kill between treatment in the first and second G1 phase might be attributed to a loss of cell-cycle synchronization by the time the cells reach the second G1 peak (30). A possible explanation for the enhanced sensitivity of cells in the G2/M phase could be that a given dose of cisplatin inflicts more damage in this phase of the cell cycle than in any other phase. An alternative explanation could be that repair mechanisms capable of correcting cisplatin-induced DNA-damage are active only during the G1/S phase. Finally, cell-cycle independent repair mechanisms may need a rather long time span to achieve relevant repair of cisplatin-induced DNA damage. In this case, the shorter interval between occurrence of the damage and activation of the apoptotic program might render the cells more sensitive to cisplatin when treated in G2/M. Even though the first explanation seems to be the most likely one, our experiments do not provide definitive confirmation of the mechanisms behind the observed phenomenon.

The question by which pathway apoptosis is induced in cisplatin-treated GCT cells was not addressed in the present study, as parameters of the execution phase common to the mitochondrial and the death receptor pathway were mainly analyzed. Recent findings on apoptosis in germ cell tumors after cisplatin exposure are controversial. On one hand, the release of mitochondria- and endoplasmic reticulum-associated apoptogenic factors, such as cytochrome $\mathrm{c}$ and Bax, activation of the initiator caspase 9 and of caspases 3,6 and 7 with downstream cleavage of PARP have been described $(31,32)$. These data suggest that cisplatin-induced apoptosis is executed via the mitochondrial pathway. On the other hand, inhibition of caspase 8 resulted in relative resistance to cisplatin, promoting the assumption of death receptor-mediated apoptotic pathway (33). Also the data on p53 are controversial. A high level of p53 has long been regarded as an explanation for the exquisite chemosensitivity of GCT $(4,5)$. However, in clinical reality, p53-mutations are exceedingly rare, as they are in refractory cases (40) in which p53 seems to function, as far as induction of apoptosis is concerned (8). Burger and coworkers described that cisplatin-induced apoptosis can be p53-independent in GCT cell lines $(41,42)$. We analyzed the expression of p53 after cisplatin exposure. We found an induction of p53 upon cisplatin treatment in the GCT cells, NT2 and 2102 EP. Similar to the kinetics of apoptosis, p53-induction was cell-cycle dependent, which correlates with p53-mediated apoptosis. A plausible explantation for this discrepancy could be a redundant pathway that takes over from p53, e.g. p73. In this case, a mutation of p53 would not establish an advantage for the tumor cell, knocking p53 out would not neccessarily result in resistance and the apoptosis could still be p53-induced in the case of persistance of the wild-type protein.

In conclusion, the presented data clearly demonstrate a cell-cycle dependence of cisplatin-induced cell death in GCT-derived cell lines. Following cisplatin exposure, cells undergo G2/M arrest and apoptosis is finally induced in this phase of the cell cycle. Furthermore, the results indicate that not only the execution of apoptosis but also the initiation of the apoptotic process, most likely by sensing the crucial cisplatin inflicted DNA damage signal, take place in this phase of the 
cell cycle. The G2/M dependence of the therapy-induced cell death is in line with the assumption of a central role of the DNA-mismatch-repair (MMR) system as the trigger of apoptosis in GCTs (34-36). The notion of MMR as the critical damage sensor in the cisplatin-based treatment of GCT corresponds to recent data from patients suffering from cisplatin refractory GCTs. In contrast to unselected GCTs, tumors from patients not responding to cisplatin have a high incidence of microsatellite-instability; a feature that indicates a defect in the DNA-mismatch-repair system (37). From a clinical point of view, the data of our analysis indicate that pharmacologically induced cell-cycle arrest of GCT cells in $\mathrm{G} 2 / \mathrm{M}$ phase might potentiate the effect of cisplatin-based treatment. On the other hand, agents inducing G1/S arrest may potentially exert an antagonistic effect.

\section{Acknowledgements}

This work was supported by grants from the the WilhelmSander-Stiftung to F.H. and F.M. (2003.122.1), and the Mathias Lackas Stiftung, the Deutsche Forschungsgemeinschaft (WE1801/1) to S.W., the German Bundesministerium fuer Bildung und Forschung (Hep-Net) to S.W., the Landesforschungsschwerpunktprogramm of the Ministry of Science, Research and Arts of the Land Baden-Wuerttemberg to S.W. and the Fortuene Program of the University of Tuebingen to K.L. and F.M. (F1282514).

\section{References}

1. Pottern ML, Brown M and Devesa SS: Epidemiology and pathogenesis of testicular cancer. In: Testicular and Penile cancer. Ernsthoff MS, Heaney JA and Peschel RE (eds). Backwell Sience, Oxford, pp2-10, 1998.

2. Bosl GJ and Motzer RJ: Testicular germ-cell cancer. N Engl J Med 337: 242-253, 1997.

3. Mayer F, Honecker F, Looijenga LH and Bokemeyer C: Towards an understanding of the biological cases of response to cisplatinbased chemotherapy in germ-cell tumors. Ann Oncol 14: 825-832, 2003.

4. Lutzker SG and Levine AJ: A functionally inactive p53 protein in teratocarcinoma cells is activated by either DNA damage or cellular differentiation. Nat Med 2: 804-810, 1996.

5. Lutzker SG, Mathew R and Taller DR: A p53 dose-response relationship for sensitivity to DNA damage in isogenic teratocarcinoma cells. Oncogene 20: 2982-2986, 2001.

6. Levine AJ: p53, the cellular gatekeeper for growth and division. Cell 88: 323-331, 1997.

7. Strohmeyer T, Reissmann P, Cordon-Cardo C, Hartmann M, Ackermann R and Slamon D: Correlation between retinoblastoma gene expression and differentiation in human testicular tumors. Proc Natl Acad Sci USA 88: 6662-6666, 1991.

8. Mayer F, Stoop H, Scheffer GL, Scheper R, Oosterhuis JW, Looijenga LH and Bokemeyer C: Molecular determinants of treatment response in human germ cell tumors. Clin Cancer Res 9: 767-763, 2003.

9. Bartkova J, Lukas C, Sorensen CS, Meyts ER, Skakkebaek NE, Lukas J and Bartek J: Deregulation of the RB pathway in human testicular germ cell tumours. J Pathol 200: 149-156, 2003.

10. Spierings DC, De Vries EG, Vellenga E and De Jong S: The attractive Achilles heel of germ cell tumours: an inherent sensitivity to apoptosis-inducing stimuli. J Pathol 200: 137-148, 2003.

11. Russell KJ, Wiens LW, Demers GW, Galloway DA, Plon SE and Groudine M: Abrogation of the G2 checkpoint results in differential radiosensitization of G1 checkpoint-deficient and G1 checkpoint-competent cells. Cancer Res 55: 1639-1642, 1995.

12. Siles E, Villalobos M, Valenzuela MT, Nunez MI, Gordon A, McMillan TJ, Pedraza V and Ruiz de Almodovar JM: Relationship between p53 status and radiosensitivity in human tumour cell lines. Br J Cancer 73: 581-588, 1996.
13. Kartalou M and Essigmann JM: Mechanisms of resistance to cisplatin. Mutat Res 478: 23-43, 2002.

14. Sorenson CM and Eastman A: Influence of cis-diamminedichloroplatinum(II) on DNA synthesis and cell cycle progression in excision repair proficient and deficient Chinese hamster ovary cells. Cancer Res 48: 6703-6707, 1988.

15. Sorenson CM and Eastman A: Mechanism of cis-diamminedichloroplatinum(II)-induced cytotoxicity: role of G2 arrest and DNA double-strand breaks. Cancer Res 48: 4484-4488, 1988.

16. Sorenson CM, Barry MA and Eastman A: Analysis of events associated with cell cycle arrest at G2 phase and cell death induced by cisplatin. J Natl Cancer Inst 82: 749-755, 1990.

17. Chao CC: Molecular basis of cis-diamminedichloroplatinum(II) resistance: a review. J Formos Med Assoc 95: 893-900, 1996.

18. Davis PK, Ho A and Dowdy SF: Biological methods for cellcycle synchronization of mammalian cells. Biotechniques 30 : 1322-1331, 2001

19. Nicoletti I, Migliorati G, Pagliacci MC, Grignani F and Riccardi C: A rapid and simple method for measuring thymocyte apoptosis by propidium iodide staining and flow cytometry. J Immunol Methods 139: 271-279, 1991.

20. Nilausen $\mathrm{K}$ and Green $\mathrm{H}$ : Reversible arrest of growth in G1 of an established fibroblast line (3T3). Exp Cell Res 40: 166-168, 1965.

21. Meyerson $\mathrm{M}$ and Harlow E: Identification of G1 kinase activity for cdk6, a novel cyclin D partner. Mol Cell Biol 14: 2077-2086, 1994.

22. Sherr CJ: Growth factor-regulated G1 cyclins. Stem Cells 12 (suppl 1): 47-55, 1994.

23. Sherr CJ: Mammalian G1 cyclins. Cell 73: 1059-1065, 1993.

24. Arata Y, Fujita M, Ohtani K, Kijima S and Kato JY: Cdk2dependent and -independent pathways in E2F-mediated $S$ phase induction. J Biol Chem 275: 6337-6345, 2000.

25. Liu YC, Chen GS, Liu WL and Wen SF: Estimation of PCNA mRNA stability in cell cycle by a serum-deprivation method. J Cell Biochem 57: 641-646, 1995.

26. Kung AL, Sherwood SW and Schimke RT: Differences in the regulation of protein synthesis, cyclin $B$ accumulation, and cellular growth in response to the inhibition of DNA synthesis in Chinese hamster ovary and HeLa S3 cells. J Biol Chem 268: 23072-23080, 1993.

27. Kung AL, Sherwood SW and Schimke RT: Cell line-specific differences in the control of cell cycle progression in the absence of mitosis. Proc Natl Acad Sci USA 87: 9553-9557, 1990.

28. Kung AL, Zetterberg A, Sherwood SW and Schimke RT: Cytotoxic effects of cell cycle phase specific agents: result of cell cycle perturbation. Cancer Res 50: 7307-7317, 1990.

29. Pardee AB: G1 events and regulation of cell proliferation. Science 246: 603-608, 1989.

30. Futcher B: Cell cycle synchronization. Methods Cell Sci 21: 79-86, 1999.

31. Sinha Hikim AP, Lue Y, Diaz-Romero M, Yen PH, Wang C and Swerdloff RS: Deciphering the pathways of germ cell apoptosis in the testis. J Steroid Biochem Mol Biol 85: 175-182, 2003.

32. Mueller T, Voigt W, Simon H, Fruehauf A, Bulankin A, Grothey A and Schmoll HJ: Failure of activation of caspase-9 induces a higher threshold for apoptosis and cisplatin resistance in testicular cancer. Cancer Res 63: 513-521, 2003.

33. Spierings DC, De Vries EG, Vellenga E and De Jong S: Loss of drug-induced activation of the CD95 apoptotic pathway in a cisplatin-resistant testicular germ cell tumor cell line. Cell Death Differ 10: 808-822, 2003.

34. Hirose Y, Katayama M, Stokoe D, Haas-Kogan DA, Berger MS and Pieper RO: The p38 mitogen-activated protein kinase pathway links the DNA mismatch repair system to the G2 checkpoint and to resistance to chemotherapeutic DNA-methylating agents. Mol Cell Biol 23: 8306-8315, 2003.

35. Marquez N, Chappell SC, Sansom OJ, Clarke AR, Court J, Errington RJ and Smith PJ: Single cell tracking reveals that Msh2 is a key component of an early-acting DNA damageactivated G2 checkpoint. Oncogene 22: 7642-7648, 2003.

36. Cejka P, Stojic L, Mojas N, Russell AM, Heinimann K, Cannavo E, Di Pietro M, Marra G and Jiricny J: Methylationinduced $\mathrm{G}(2) / \mathrm{M}$ arrest requires a full complement of the mismatch repair protein hMLH1. EMBO J 22: 2245-2254, 2003.

37. Mayer F, Gillis AJ, Dinjens W, Oosterhuis JW, Bokemeyer C and Looijenga LH: Microsatellite instability of germ cell tumors is associated with resistance to systemic treatment. Cancer Res 62: $2758-2760,2002$. 
38. Hong Y and Stambrook PJ: Restoration of an absent G1 arrest and protection from apoptosis in embryonic stem cells after ionization radiation. Proc Natl Acad Sci USA 101: 14443-14448, 2004.

39. Oosterhuis JW and Looijenga HJ: Testicular germ-cell tumours in a broader perspective. Nat Rev Cancer 5: 210-222, 2005.

40. Kersemaekers AM, Mayer F, Molier M, van Weeren PC, Oosterhuis JW, Bokemeyer C and Looijenga LH: Role of P53 and MDM2 in treatment response of human germ cell tumors. Clin Oncol 20: 1551-1561, 2002.
41. Burger H, Nooter K, Boersma AW, Kortland CJ and Stoter G: Expression of p53, Bcl-2 and Bax in cisplatin-induced apoptosis in testicular germ cell tumour cell lines. Br J Cancer 77: 1562-1567, 1998.

42. Burger H, Nooter K, Boersma AW, van Wingerden KE, Looijenga LH, Jochemsen AG and Stoter G: Distinct p53independent apoptotic cell death signalling pathways in testicular germ cell tumour cell lines. Int J Cancer 81: 620-628, 1999.

43. Wang N, Perkins KL, Bronson DL and Fraley EE: Cytogenetic evidence for premeiotic transformation of human testicular cancers. Cancer Res 41: 2135-2140, 1981 